\title{
O Radiômetro de Crookes é um cata-luz
}

The Crookes's Radiometer is a light vane

\author{
José Joaquín Lunazzi*1일 Antonio Marcos de Souza ${ }^{10}$ \\ ${ }^{1}$ Universidade Estadual de Campinas, Instituto de Física, Campinas, SP, Brasil.
}

\begin{abstract}
Recebido em 23 de Agosto de 2020. Revisado em 17 de Outubro de 2020. Aceito em 18 de Outubro de 2020.
Dentre os experimentos mais importantes do século XIX está um que liga o eletromagnetismo com a mecânica de forma direta. No chamado "Radiômetro de Crookes" a luz, empurrando palhetas, surpreende dando a imediata percepção de sua energia. O público percebe que o lado preto é quem recebe a maior ação. O estudante de escola, e o universitário, tentam entender o porquê disso, mas ficam com dúvidas. Neste artigo fazemos um recenso das dúvidas que acontecem, em nível de escola, graduação, e pós-graduação. É comum pensar em termos de eletromagnetismo, de termodinâmica, mas não conhecemos artigo algum que tenha incluído o atrito na análise. Mostramos aqui a influência do atrito por meio de um experimento simples.
\end{abstract}

Palavras-chave: Óptica, força da luz, fóton, experimentos didáticos, vela solar.

One of the most important experiments of the 19th century makes a connection between electromagnetism and mechanics in a direct way. In the so called "Crooke's Radiometer" the light, pulling vanes, surprises us giving the immediate perception of its energy. The public perceives that is the black side which receives the greater action. The school and the universitarie's students, they try to understand why it is so, but doubts remain. In this article we make a review of those doubts at three levels: school, graduation and post-graduation. The usual thinking employs electromagnetism, thermodynamics, but we do not know any article which who may had included friction on the analysis. We show here the influence of friction by performing a simple experiment.

Keywords: Optics, light energy, photon, didactical experiments, solar sailing.

\section{Introdução}

O radiômetro é um instrumento contendo palhetas movidas a luz e que evidencia a presença e a intensidade da radiação de luz proveniente de uma fonte. Por ter sido desenvolvido por William Crookes no ano de 1873, ficou conhecido como "Radiômetro de Crookes". Ele é formado por um bulbo de vidro, contendo quatro hélices (palhetas) metálicas igualmente espaçadas e apoiadas em uma haste metálica com uma ponta fina no eixo vertical. A ponta encaixa em um semi-tubo de vidro, central ao sistema de palhetas. As quatro palhetas bem finas possuem cores branca de um lado e preta do outro. O bulbo está parcialmente sem ar, em vácuo parcial. A foto de um radiômetro é mostrada na Figura 1

O Radiômetro de Crookes é muito popular nos EUA, e barato, ao preço de um maço de cigarros. No entanto, é um experimento muito raro no Brasil e encontra-se disponível apenas através de importação. $\mathrm{O}$ aparelho é bem frágil e pode quebrar no transporte e na manipulação. Depois de uma introdução áudio-visual [1] sobre a energia da luz e a vida, ele é o primeiro experimento da exposição "Veja a luz como nunca viu" [2, criada e desenvolvida pelo Prof. Dr. José Joaquín Lunazzi, na Unicamp, em 2015, pelo Ano Internacional da Luz, designado como o foi pela Unesco. A exposição é constituída

\footnotetext{
* Endereço de correspondência: lunazzi@ifi.unicamp.br
}

por diversos experimentos realizados durante a trajetória profissional do Prof. Lunazzi, com alto nível de elaboração e originalidade. Desde doze anos antes o Prof. Lunazzi ministrava as disciplinas de Graduação e Licenciatura "F 809-Instrumentação para o ensino", "F 609-Tópicos de Ensino de Física I" e "F 709Tópicos de Ensino de Física II" [3, 4] onde cada aluno desenvolvia um experimento didático individualmente, e alguns deles foram sendo aplicados no evento de divulgação "Exposição de Holografia" [5] feito para auditório seguido de quatro salas com experimentos. Vale destacar que os experimentos foram elaborados, em sua maioria, com materiais de baixo custo e de simples aquisição. A exceção é o radiômetro, que foi feito com tecnologia de laboratório na disciplina F 809 "Instrumentação para o ensino" 6, 7] mas que guardamos como referência enquanto utilizamos um importado [8]. A exposição "Veja a luz como nunca viu" está hoje situada no Laboratório de Óptica do Instituto de Física da Unicamp. Os vinte e dois experimentos são apresentados aos alunos da educação básica, a professores, e também aos visitantes em geral, da região de Campinas e de outras localidades do país. Já recebeu e vem recebendo a visita de estudantes (anos finais do ensino fundamental e ensino médio) que, acompanhados de seus professores, agendam datas e horários para a visita. $\mathrm{O}$ radiômetro justifica já no início o nome do evento pois eles nunca viram a luz empurrar algo. Os estudantes têm 


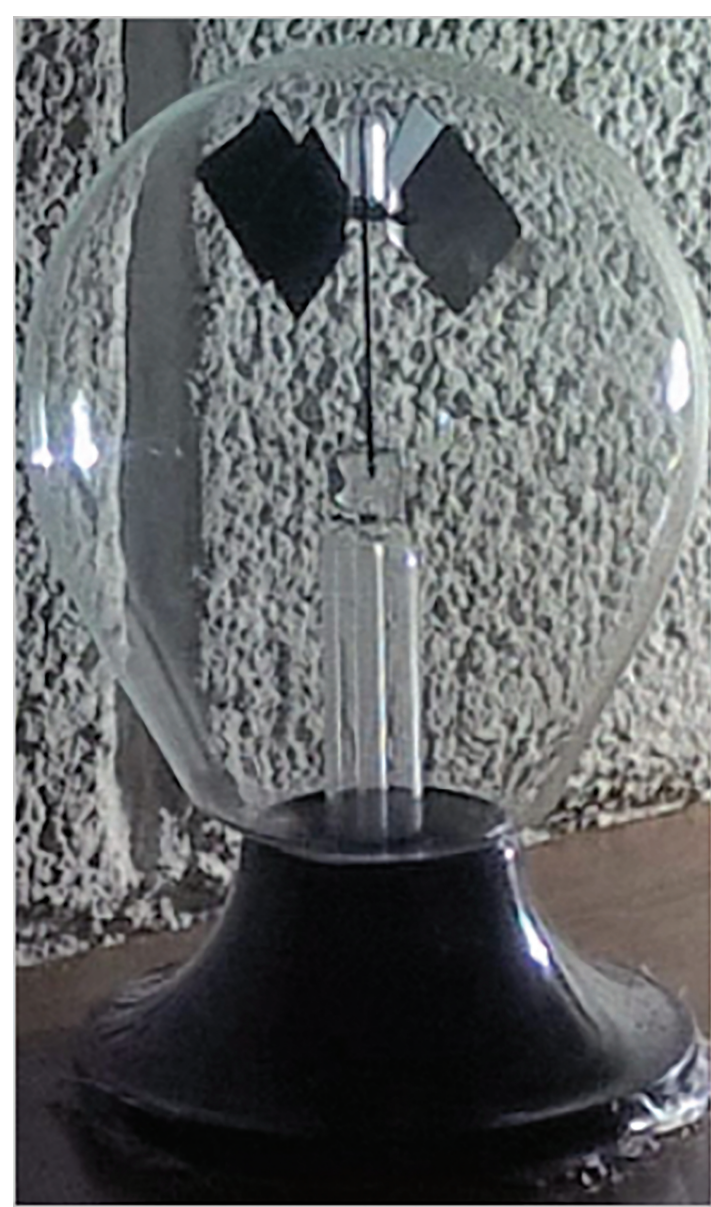

Figura 1: Radiômetro de Crookes.

a oportunidade de compreender e discutir seu funcionamento com diversas questões apresentadas pelo professor coordenador e monitores. As discussões sobre o funcionamento do experimento, considerado pela maioria como demonstrativo, leva professores e estudantes a questionamentos qualitativos sobre o funcionamento do radiômetro e de outras leis ou fenômenos físicos envolvidos. Já seja pelo Prof. Lunazzi ou pelos seus monitores, demonstra-se a energia da luz sendo diretamente convertida em movimento mecânico, e prova-se que a luz não tem massa pelo fato evidente de que atravessa o vidro. $\mathrm{Na}$ evidência de que estão sendo empurradas as palhetas pelo lado preto, a pergunta que alguns fazem, talvez pela comparação com as lâmpadas de tungstênio, que tem o mesmo formato, é se dentro tem vácuo. Alunos de graduação logo notam que, pela teoria que aprenderam, ele deveria girar ao contrário, uma consequência da variação da quantidade de movimento. Alunos de pós-graduação ficam tentando entender pela teoria eletromagnética ou pela teoria quântica, mas também não chegam à explicação. Nossa análise percorre esse caminho sem definir a solução, mas percebendo que o atrito não foi considerado na bibliografia. Destacamos o momento inicial, onde é evidente que há uma demora desde o momento de iluminar até o giro começar, algo que nunca é comentado e que faz evidente que acontece um acúmulo de energia. Destacamos também a presença do atrito estático e sua conversão em dinâmico. Criamos um experimento simples com controle do fluxo luminoso para observar a conduta do atrito.

\section{O Funcionamento Básico do Radiômetro}

$\mathrm{Na}$ literatura e nas diversas postagens da internet (principalmente em vídeos) encontramos sempre explicações semelhantes sobre o funcionamento do radiômetro, o qual consiste em colocar uma fonte de luz ou de radiação infravermelha, natural ou artificial, próxima ao bulbo contendo as palhetas, estas apoiadas na haste vertical e, se a intensidade for suficiente, após alguns instantes as palhetas começam a girar. Sabemos que as palhetas de cor preta convertem a radiação em calor em maior quantidade do que as de cor branca, clara ou refletiva. Isto faz com que o ar (rarefeito) próximo às palhetas escuras fique mais agitado do que o ar próximo às claras [9]. Poder-se-ia pensar em uma corrente ascendente e um efeito de Bernoulli oposto ao movimento, mas é fato que uma força maior do que no lado claro acontece depois de um instante e inicia o movimento. Embora o nome dado ao aparelho indique que ele mede, algo que parece ser indicado na parte "metro" dele, nenhuma das referências que encontramos faz menção ao uso efetivo do aparelho como medidor. Faz pensar em um medidor de radiação, como o espectrômetro, o fotômetro, torquímetro, pluviômetro etc., porém não vemos como o aparelho poderia servir para medir a quantidade de luz que recebe. No momento da partida podemos pensar que há uma demora em alcançar a temperatura necessária para ter força que supere a inércia das palhetas, eventualmente do ar que empurram, mas a inércia nunca impede o movimento, só o demora, de maneira que temos de incluir ao atrito em nosso raciocínio, o do ar, e em particular, o atrito mecânico no eixo. O termo mais correto seria talvez "fotomóbil". Em inglês usa-se o termo mais popular "moinho a vento" ("windmill"), que também não é senão uma semelhança, pois um moinho é utilizado para aproveitar energia mecânica e neste caso não sobra nada dela que se possa aproveitar. No Brasil nós acabamos de adotar o nome de "cata-luz" por semelhança com o cata-vento, brinquedo popular que pela ação do vento gira suas aspas coloridas. Elemento que faz parte também das veletas, aparelho colocado no teto de uma casa para indicar a direção e, pelo catavento que tem na frente, a intensidade do vento. $\mathrm{O}$ nome foi sugerido a pedido nosso por uma artista plástica que visitou nosso evento 1

\footnotetext{
1 Resultado da visita das assessoras Marcela Gomes Pupatto e Fabia Pereira Branco do Centro Cultural SESC-Pinheiros à exposição "Veja a Luz Como Nunca Viu", no local do Laboratório de Plasma, Instituto de Física, Unicamp, Campinas-SP, 15 de agosto de 2018 .
} 


\section{Maneiras de se Exibir o Radiômetro}

Tradicionalmente, a maioria dos experimentos didáticos de física é feita para serem observados em volta de uma mesa de trabalho. As pessoas ficam em volta e podem até manipular, conduta estabelecida pelo Prof. Lunazzi para os monitores adotarem, sob ameaça (cordial) de algemas. No andamento das disciplinas de Licenciatura citadas 3, 4, foi se percebendo como nas escolas da cidade e cidades vizinhas o número de alunos por sala de aula ia aumentando sem controle e não mais era viável pensar em ter atividade em mesas na escola. A disciplina passou a estimular o desenho de maneira que os experementos pudessem ser vistos por uma audiência maior. A silueta deles podendo ser projetado com um retroprojetor, equipamento de que toda escola dispunha. Lembrando da maneira em que antigamente, na Europa, EUA e Argentina, ao menos, se ensinava Física nas faculdades: Em um grande anfiteatro, com até 300 pessoas, na bancaa do professor o experimento podia ser visto por todos. E isto, antes de começar com a teoria [10, 11. No caso de nosso aparelho ele é mostrado agora em uma sala pequena mas a luz da lâmpada de filamento reto de tungstênio que o aciona projeta uma sombra grande na parede branca e a visão do movimento resulta mais interessante e emocionante (Fig. 22). O mesmo foi feito em um anfiteatro, mesmo tendo uma câmera para mostrar o experimento [12, pois apreciar de modo não digital nem eletrônico aproxima ao público da realidade, já que na tela digital os jovens vivem hoje em dia, diariamente, muitas fantasias que resultam da edição e processamento das cenas.

\section{Conduta do Radiômetro nas Mudanças de Temperatura}

É fácil de comprovar que esquentar o radiômetro faz ele girar empurrado pelo lado preto das palhetas. E esfriando-o, gira no sentido contrário. Para interpretar isto temos de aceitar a ideia de que superfícies pretas retém a agitação das moléculas por mais tempo que as claras. Estando em equilíbrio térmico inicialmente, ao esquentarmos o bulbo esquentamos o ar, e essa energia maior de suas moléculas é mais absorvida pelo lado preto das palhetas, e com ela gera-se o movimento por esse lado. Já ao esfria-lo, o lado claro transfere com mais facilidade ao ar a energia cinética de suas moléculas, recebendo mais empuxo pelo efeito de reação. Um vídeo nos mostra bem este efeito assim como, por outro lado, a relação entre pressão e rotações [13].

\section{O Radiômetro de Crookes vs. o Cata-luz: Exposição e o Confronto de Ideias}

É evidente que a força que movimenta é devida à energia da radiação, que é devolvida em maior grau pelo

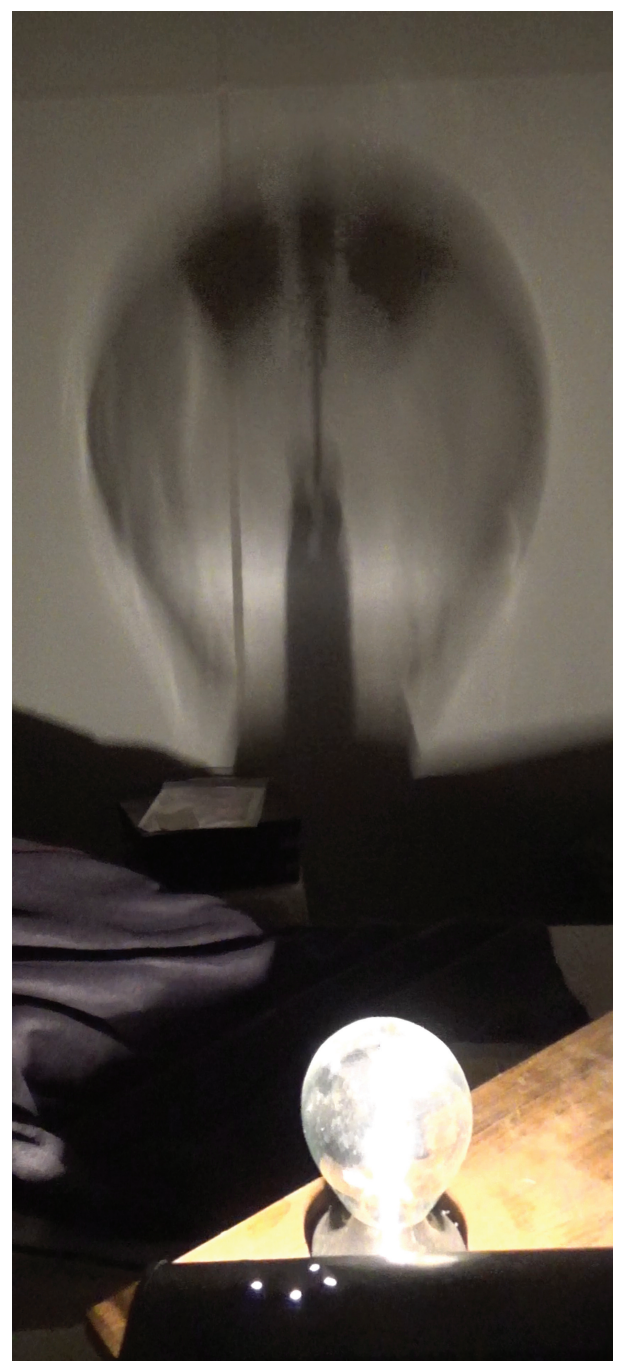

Figura 2: Visualização ampliada do cata-luz por meio da sombra de sua própria lâmpada no local do evento Veja a luz como nunca viu".

lado claro das palhetas, enquanto é absorvida pelo lado escuro. Gibbs [14] diz que não seria certo considerar que o aquecimento nas superfícies absorventes gera o movimento, e para isso ele utiliza um modelo de gás ideal em equilíbrio térmico. Nossa consideração é que o equilíbrio que considera um tubo isolado termicamente não vale pois há um esfriamento através da esfera de vidro do radiômetro, algo que foi evidente quando experimentamos e a temperatura do ambiente estava diminuindo e logo vimos o efeito disso no movimento. Desta maneira, em nossa visão, o aquecimento maior gera colisões intermediando entre a massa das palhetas e a do ar, no que, por ação e reação, algo dessa energia empurra às palhetas. O calor vai se espalhando dentro do bulbo, mas se dissipando pelas suas paredes (Figura 3). Este fenômeno faz com que, quando a palheta faz uma volta, esteja novamente na temperatura média, pronta para receber mais calor, e não aumentando constantemente de temperatura. 


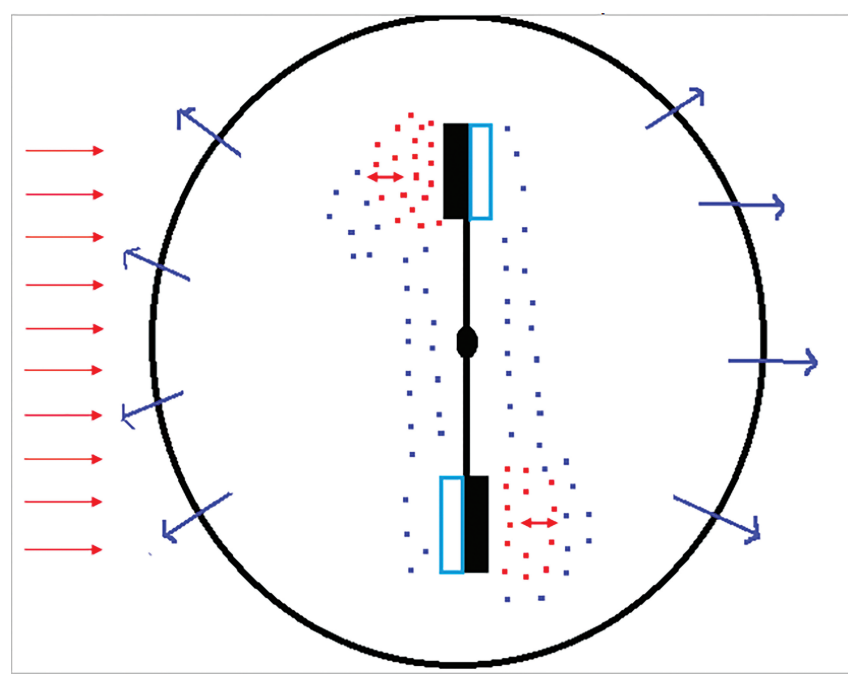

Figura 3: Representação que inclui a dissipação pelo bulbo.

A Figura 3 mostra a radiação incidindo pela esquerda, e o lado escuro das palhetas dando mais temperatura às moléculas de ar próximas. Estas, colidindo entre a palheta e a massa de ar mais distante, o que gera um efeito por ação e reação de afastamento de ambos, embora em quantidades não iguais. Tanto pela movimentação interna do ar, possivelmente turbulenta, como pela distribuição de calor, onde o calor adquirido pelas moléculas mais frias é dissipado através do vidro e elas voltam à temperatura anterior. Desta maneira se explica também o caso das palhetas terem em todas as faces a mesma cor e, tendo forma semiesférica, girarem à maneira de um anemômetro [15].

Vemos na Figura 4 que se houver efeito de bordas, a força $(\mathrm{Fb})$ seria em direção que não pode gerar movimento, enquanto que as superfícies, mesmo tendo recebido a mesma energia térmica pela radiação, esquentam as moléculas em volta gerando colisões. Sabemos que estas colisões distribuem o calor das moléculas das mais quentes às mais frias. Nas superfícies convexas, as colisões esquentam o ar afastando o calor delas. Nas côncavas, a energia recebida fica mais próxima da interação acontecendo novamente na superfície, e é portanto pelo lado côncavo que as palhetas seriam empurradas. Nos chama muito a atenção que, em uma época na que partículas estão sendo manipuladas pela luz na forma de pinças ópticas, o mecanismo não tenha sido evidenciado. Em 1970 [16] foi demonstrado que um feixe de laser pode acelerar, desacelerar, e capturar partículas. É claro que este processo também está ligado às considerações que temos respeito do experimento, mas não vamos analisar agora. Havendo tantas propostas de modelos de palhetas que aumentassem a extensão das bordas, como no formato espiral, e este de formato côncavo, não encontramos referências onde mais experimentos e teoria acabassem com as dúvidas. Temos, no entanto, um trabalho tentativo [17, com palhetas

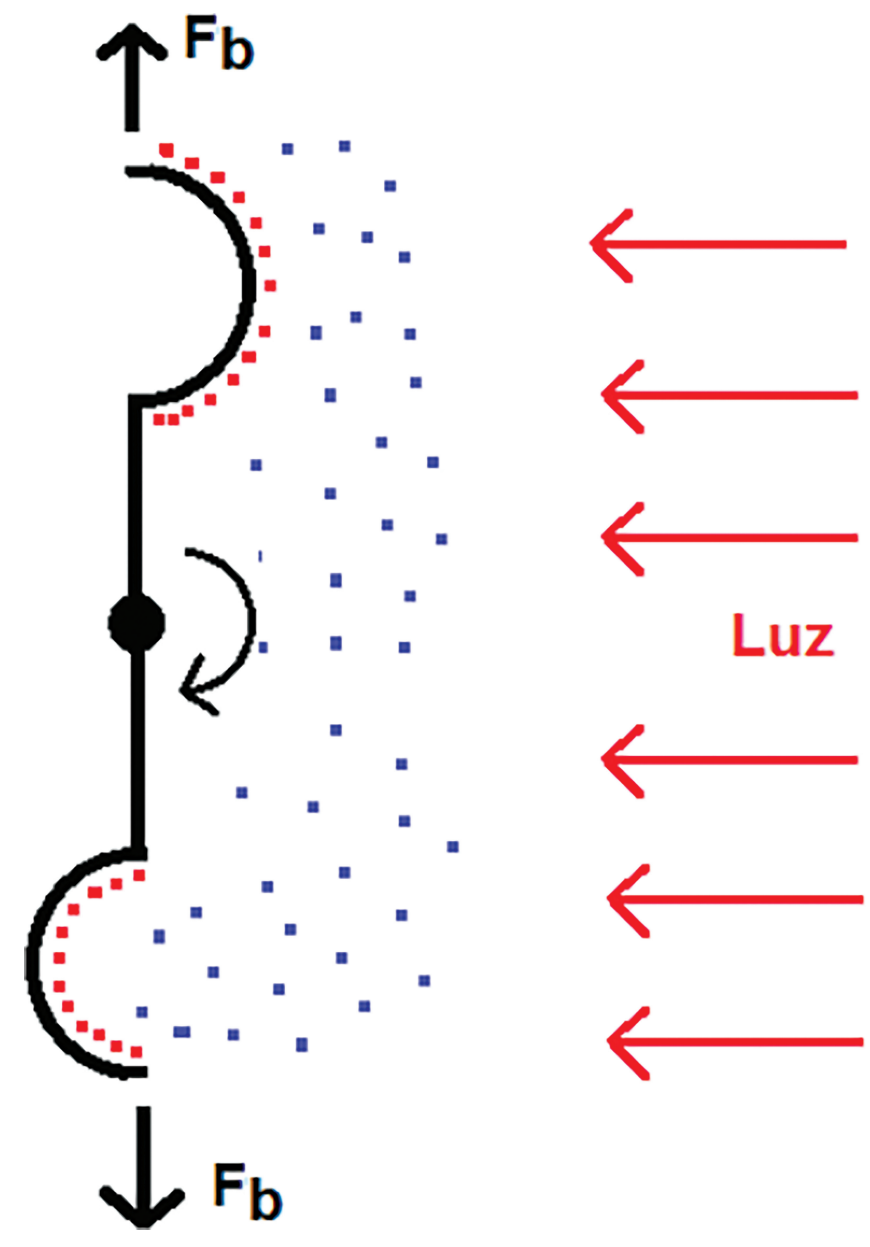

Figura 4: Caso de palhetas tendo formato semiesférico.

horizontais mas que não é conclusiva no casamento entre teoria e experimento, chegando a uma ordem de magnitude de diferença entre valores. E um trabalho recente [18, parte dos trabalhos microscópicos de pinças ópticas e, alterando o formato de uma palheta encontra uma surpreendente inversão do empuxo. É muito comum nos cursos da universidade ensinar que o aparelho deveria girar sendo empurrado pelo lado claro, argumentando que a mudança da quantidade de movimento da luz é o dobro nesses lados, fazendo uma analogia mecânica discutível posto que a luz é uma onda, não tem massa, e não poderia ser tratada como um jato de minúsculas bolinhas à maneira que Newton concebeu. Embora uma explicação dada por Maxwell e Reynolds [15, 19] indica que não é um caso de pressão de radiação, senão de termodinâmica correspondente a um fenômeno nas bordas sendo consideradas como superfícies porosas que levam o ar por dentro do lado frio para o quente, não se consegue entender como um tal fenômeno poderia levar à inversão do sentido de movimento pois isso parece não respeitar a conservação da energia.

O funcionamento do aparelho seria mais compreensível se houvesse um claro equacionamento do valor da energia transferida pela luz a uma superfície, e de 
todo o funcionamento do aparelho, no qual pudessem ser incluídos os parâmetros experimentais e confirmado o resultado pelas medições. Esse problema envolve mais que o da pressão de radiação e a termodinâmica, pois inclui o deslocamento da superfície sendo empurrada. A abordagem da teoria poderia ser feita por eletromagnetismo clássico, sendo que o próprio Maxwell já avaliou e discutiu o Radiômetro de Crookes. Também, pela teoria quântica, que considera o efeito da luz a partir da ação de unidades mínimas e indivisíveis de energia, os fótons, mas parece requerer de um tratamento muito mais complexo [20, 21, ainda para o nível de escola, e mesmo de universidade. Um modelo clássico será sempre o elemento primário para uma análise. Trata-se, na essência, da própria concepção da luz, que não pode ser considerada como partícula pois não tem massa, e portanto resulta discutível se aplicar as leis de Newton nela.

Vemos em uma referência muito comum [22] que a pressão de radiação da luz sobre uma superfície fixa é explicada invocando a Maxwell, quem teria demonstrado que a luz refletida gera o dobro de pressão de radiação sobre uma superfície refletora se comparado ao caso de uma superfície absorvente, e isto seria porque a luz tem quantidade de movimento. A partir daí o autor passa a explicar o fenômeno por analogia com a mecânica de uma bola elástica, deixando de considerar que uma onda é pura energia. Analogias até podem ser úteis desde que se indiquem as diferenças entre o fenômeno verdadeiro e sua analogia, pois podem levar à maioria dos professores e estudantes a erro, tanto que vemos como hoje é muito comum eles pensarem na luz como composta de partículas, sendo que a ideia física de partícula, desde sua origem, é a de um elemento com massa. Argumenta-se que a quantidade $\frac{\Delta U}{c}$, mudança da quantidade de energia proporcionalmente à velocidade da luz no vácuo, é equivalente a uma quantidade de movimento. O seria matematicamente, porém não podemos impunemente mudar elementos de um lado a outro de uma igualdade e pretender que a natureza vai agir conforme nossa manipulação algébrica. A célebre equação popularizada por Einstein $\mathrm{E}=\mathrm{mc}^{2}$ indica que para uma certa quantidade de massa é possível a conversão em uma quantidade de energia segundo a expressão. Isto ficou notório depois que as bombas atômicas começaram a explodir, uns poucos átomos gerando transformações de energia capazes de deslocar enorme quantidade de outros átomos. Se, agora, colocamos a expressão como $\mathrm{m}=\frac{E}{c^{2}}$ deveríamos interpretar que uma certa quantidade de energia, por exemplo luminosa, pode nos proporcionar uma certa quantidade de massa, e isto é algo que nunca se observou desta maneira direta, sem a intervenção de partículas intermediando o processo (efeito Compton). Precisamos então ser muito cuidadosos nos termos que utilizamos ao ensinar física na escola para não gerar interpretações errôneas. Preferimos considerar a luz como onda e com a pressão que lhe corresponde [23]: $\frac{\mathrm{Fx}}{A}=\frac{1}{C} \mathrm{~S}$
Já na escola secundária argentina, nos anos '40, ensinava-se que os fótons eram pacotes de energia, definição que não leva a confusã ${ }^{2}$ Como consequência da teoria, quando o público vê o experimento, aqueles que estudaram electromagnetismo e óptica associam o movimento ao caso que temos referido, e esperam que ele seja a consequência da luz empurrando as palhetas pelo lado refletor.

\section{A luz Não Tem Massa, Portanto Não é Partícula}

Além de a luz atravessar o vidro, outro elemento que evidencia sua ausência de massa é o fato de podermos ver galáxias distantes muito longe da Terra, sem que a luz que viaja resulte afetada por colisões entre seus elementos e sem que a luz do sol, que é muitíssimo mais intensa que a que recebemos, a desvie ou altere. Luz não interage com nêutrons. É preciso corrigir o falso conceito atual que resulta do excessivo uso da menção ao fóton como o elemento que constitui a luz, isto cada vez mais aparece nos comentários e textos [15, 24. Entendemos que é desnecessário falar em fóton se não há efeitos elementares em jogo, como seria em casos específicos de absorção e emissão da luz pela matéria, na radiação de corpo negro e no efeito fotoelétrico. "Não pronunciarás o nome dele em vão". Seria como se falássemos do aquecimento de um forno elétrico, p.ex., dizendo que consiste de uma sucessão de pulsos elétricos de 1/120 s (Figura 5) consecutivos se ligando sendo que, a partir do momento em que atribuímos uma energia média baseada na amplitude, o processo pode ser tratado como contínuo. Falaríamos em uma sequência de períodos a respeito do funcionamento de um forno de microondas?

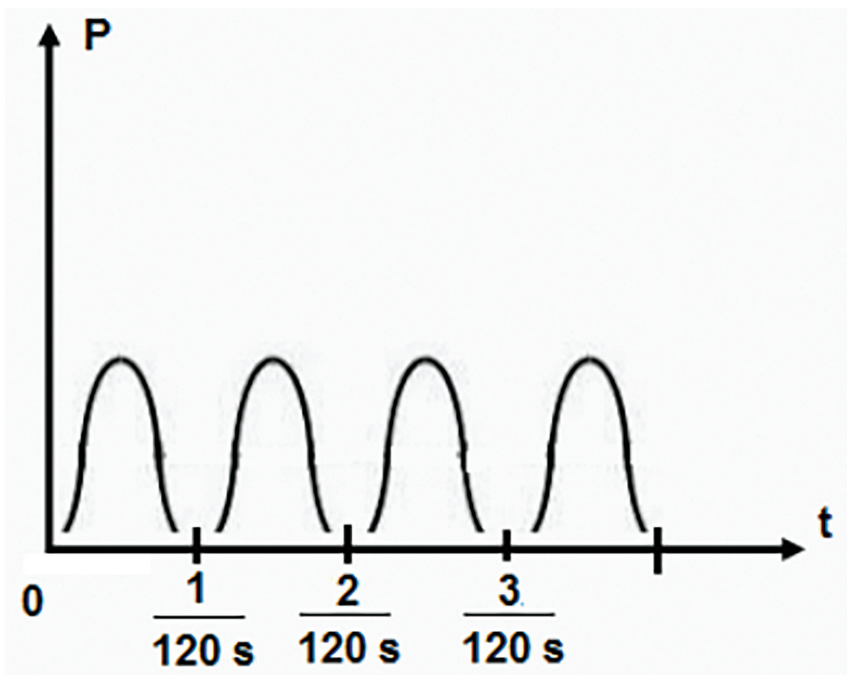

Figura 5: Gráfico da potência a $120 \mathrm{~Hz}$ interpretado como sequência de pulsos.

\footnotetext{
2 Otília Martinez Ungría, "In Memorian”, depoimento pessoal, La Plata, Argentina, 1962
} 
Embora o elemento fundamental da eletricidade seja uma partícula que além de carga possui massa, a energia elétrica é transferida nos fios condutores por meio de uma onda!. Os elétrons que estão em um extremo do fio condutor, não são os mesmos que agem no extremo oposto. Vemos hoje em demonstrações didáticas de eletricidade a crianças perguntando pelos elétrons, e nas de óptica pelos fótons, querendo vê-los. Mas, infelizmente, isso não é possível. Como poderíamos explicar que o tal do fóton tem uma frequência única bem definida, mas extensão e duração que não saberíamos definir?. E, sendo a duração dele muito breve, logo surgiria a questão, a nível de graduação, de que poderia ter uma decomposição de Fourier, como qualquer pulso, o que lhe impede de ter frequência única. Para complicar mais a questão, temos que o momento do fóton em um meio não é ainda conhecido, havendo duas teorias opostas para isso, uma de que ele aumenta, outra de que diminui, a controvérsia não tem prova experimental ainda 25 .

\section{Velejar No Espaço Sideral}

Há um projeto de nave espacial propulsada pela luz solar que a Planetary Society [26] pretende colocar logo no espaço, embora a teoria não esteja experimentalmente comprovada 27] nem os resultados práticos bem estabelecidos. Um reconhecido e instigante pesquisador inglês, Thomas Gold [28, se referindo ao projeto de vela solar espacial [29], disse que ele não poderia funcionar, porque um espelho perfeito não poderia receber empuxo; que é errado querer aplicar a teoria mecânica de conservação da quantidade de movimento à luz, que não tem massa. E uma vela absorvente, no espaço sideral, só receberia energia até o estabelecimento do equilíbrio térmico, intervalo de uns poucos segundos. Sabemos que o corpo que recebe radiação acaba re-emitindo energia, a Terra por exemplo, em estado de equilíbrio térmico, recebe energia do Sol e emite radiação infravermelha. Gold dá como exemplo o Radiômetro de Crookes, que só é empurrado pela parte absorvente. E deduzimos que ele aceita esse movimento pelo fato de que está havendo uma transferência de energia ao meio que não geraria um estado de equilíbrio térmico, que o lado escuro de uma palheta fica se esfriando enquanto dá quase uma volta inteira até receber novamente o calor da luz iluminadora. Essa é também a nossa interpretação na discussão do experimento, que não temos visto em referência alguma. O importante da manifestação de Gold, destacamos, é que nega o efeito na parte refletiva, portanto, nunca haveria movimento no sentido oposto no caso de vácuo maior. E o caso é que não se verificou movimento algum no experimento de Crookes que mostrasse empuxo pelo lado claro das palhetas. Lebedev [30] e Nichols [31] há um século verificaram o empuxo na parte refletiva sendo sempre maior que na parte absorvente, mas em um elemento único, estático, não em palhetas. E nos surpreende não conhecer mais que dois autores que tenham repetido o experimento mais recentemente e com melhores instrumentos, e que não apareça um experimento assim nos laboratórios didáticos modernos. Sequer a maneira de se medir a energia da luz, o bolômetro, aparece nos experimentos didáticos no país. Uma referência recente mede o empuxo da luz em um material bem menos absorvente que um espelho, uma rede difrativa, proposto como vela solar 32 . Devemos, por outro lado, diferenciar a ideia de uma vela solar espacial de uma palheta do radiômetro, pois no espaço temos as partículas emitidas pelo sol, normalmente não consideradas ou não avaliadas até por autores relativamente recentes e abrangentes desta problemática [33. Em tempos antigos pensou-se que a cauda dos cometas era dirigida pelo Sol por causa de sua luz, até se saber que ele emite também partículas, que têm poder de colisão direta com as que acompanham aos cometas. O atual telescópio espacial Webb [34] vai ser colocado no único ponto sem gravidade que temos ao alcance, e não é perto: onde a atração da Terra e o Sol se cancelam, restando ainda alguma influência para a Lua. Ele está desenhado para refletir sobretudo a radiação infravermelha, e essa superfície refletiva, se efetivamente estiver recebendo empuxo do Sol, vai requerer um tanto de combustível da nave para manter ao telescópio no ponto de equilíbrio instável onde será colocado.

\section{O Radiômetro e o Atrito}

Percebendo que a explicação não é clara para nós, portanto também não para um leigo, atentamos para outro elemento do experimento: Não encontramos referência que falasse em atrito, e, embora a parte "metro" do termo "radiômetro" indicaria aparelho medidor, entendemos que não é possível se medir energia recebida se não se tem o valor do atrito. Se simplificarmos o atrito em dois valores, como é tradicional nos livros de texto: o estático e o dinâmico, seria preciso conhecer o valor do atrito dinâmico para considerar a energia de rotação das palhetas e daí saber a fornecida pela luz. Notamos no experimento que há uma demora entre o momento de iluminar e a partida das palhetas, e entendemos que a superfície preta fica se aquecendo e aumentando a pressão até que ela é suficiente como para ter um torque que supere o atrito estático, já que o dinâmico é sempre menor. Pensamos em iluminar com uma intensidade logo abaixo da que permite que comece a funcionar, e girar o aparelho no sentido que normalmente anda empurrado pela luz, levando-o pelo atrito estático a girar, mas freando rapidamente para ele continuar a girar por inércia quebrando o atrito estático e girando ainda um pouco, e então a luz vai permitir que ele continue girando pois só teríamos atrito dinâmico. Assim, fizemos o experimento medindo valores de tensão da lâmpada iluminadora. Colocamos luz dando um valor tal que começou a girar, e então reduzimos ao menor valor com que continuou girando. Foi preciso isolar completamente ao sis- 
tema de correntes de ar. Depois, com esse valor mínimo de tensão, obstruimos a luz até que o aparelho parou, e, ao desobstruir e conferir que não partia, entendemos que a demora em iniciar é porque a repulsão da palheta por colisões das moléculas dela com o ar não é suficiente para quebrar o atrito estático. Ao acumular energia aquecendo o meio absorvente, que tem capacidade calorífica maior e tempo de condução menor, as colisões acabam sendo mais intensas, daí ele começa a girar após superar o atrito estático. E fizemos o experimento seguindo essas ideias, mas simplesmente chacoalhando o aparelho,

Fizemos um toque na base dele que agitou as palhetas em movimento oscilatório, e foi então que ele começou a girar, com sucesso! [35].

Verificamos assim uma situação natural do experimento, mas que ainda assim, não nos habilita a o utilizar como um medidor de energia luminosa.

\section{Conclusões}

Reafirmamos a ideia de que em mais de um século um aparelhinho pequeno, popular e barato, ainda não foi suficientemente estudado como para que seu funcionamento possa ser entendido e em consenso. Falta experimentar com novos modelos de palhetas, quem sabe até com peso anulado e no vácuo do espaço sideral, chegando a entender a situação em alto vácuo. É preciso resolver o paradoxo da inversão do movimento, mostrar a teoria e seu casamento experimental, e confrontar as diferentes ideias a respeito do experimento, como as que introduzimos no artigo, é algo que esperamos ver acontecer. Certamente que o atrito, que incluímos pela primeira vez como elemento do processo, não pode ser deixado de lado.

\section{Agradecimentos}

Ao Programa de Pós-Graduação Multi-unidades em Ensino de Ciências e Matemáticas-PECIM da Unicamp por acolher o trabalho de doutoramento de Antonio Marcos de Souza. Ao Prof. Pablo Lima Saldanha da Universidade Federal de Minas Gerais por ter atendido nossas consultas a respeito do tratamento eletromagnético clássico da pressão de radiação. Aos profs. Sérgio Gama, Dirceu da Silva e Mônica Cotta por ter orientado aos alunos José R. Mialichi, Wagner P. G. Soares e Everton G. Gadret nos trabalhos de construção de radiômetros na disciplina de Instrumentação para o ensino de física F 609, "Tópicos de Ensino de Física I" do Instituto de Física da Unicamp. Aos técnicos da Oficina de Vidraria Ademir Carlos Camillo e do Laboratório de Criogenia e Vácuo Renato Lopes Souza pelos trabalhos em vidro e vácuo. Ao físico Mark Anthony Barrios Mamani pelo trabalho de edição de nosso vídeo citado. "In Memorian" ao Prof. Carlos Alfredo Arguello, que fundou em 1978 o Laboratório de Óptica do Instituto de Física da Unicamp, onde este trabalho foi desenvolvido, quem criou o Museu Dinâmico de Ciências da
Prefeitura Municipal de Campinas e iniciou no referido Instituto os trabalhos de Pós-Graduação em Ensino de Física, vindo a falecer exatamente no momento em que estamos encerrando a redação do manuscrito deste trabalho. Ao Colégio Rio Branco de Campinas que, com o Prof. Bruno A. Ferreira colocou em 2015 em treinamento uma equipe de estudantes ajudando a montar a Exposição "Veja a luz como nunca viu". Ao Engo. Francisco Lunazzi por ter trazido em mãos radiômetros comprados nos EUA com recursos próprios da família, nos liberando da cobrança de impostos de importação. À Coordenação de Aperfeiçõamento de Pessoal de Ensino Superior-CAPES-MEC que mantém aberto às universidades o acesso a muitas revistas importantes que, de outra maneira, não teriamos como pagar para ler. À University of Cornell-EUA pela manutenção do repositório de artigos publicados ou manuscritos Arxiv que fornece acesso livre a milhões de artigos importantes na área de Ciências Exatas e de Ensino de Física. À rede social mundial gratuita de pesquisadores Research Gate, que possibilita a leitura de artigos publicados e de projetos e a comunicação entre os membros.

\section{Referências}

[1] https://www.youtube.com/watch?v=TL9dwM-8DEA

[2] https://www.ifi.unicamp.br/lunazzi/pagina_EaF/Vejaa luzcomonuncaviu.htm acessado em 30/07/2020.

[3] Sítios de "F 809-Instrumentação para o ensino", "F 609-Tópicos de Ensino de Física I" http://www. ifi.unicamp.br/ lunazzi/F530_F590_F690_F809_F895/F8 09.htm

[4] Sítio de "F 709-Tópicos de Ensino de Física II" http:// www.ifi.unicamp.br/ lunazzi/F530_F590_F690_F809_F8 95/F709_atendimento_a_escolas.htm

[5] http://www.ifi.unicamp.br/ lunazzi/expo.htm

[6] E.G. Gadret, M.A. Cotta, J.J. Lunazzi, Radiômetro de Crookes III, disponível em https://www.ifi.unicamp.br/ lunazzi/F530_F590_F690_F809_F895/F809/F809_sem 2_2006/EvertonG_Monica_RF.pdf

[7] Vídeo correspondendo à Ref. 6: "Radiômetro de Crookes (Cata-luz) feito no Instituto de Física da Unicamp": https://youtu.be/B51Yxd3OFXg

[8] www.tedcotoys.com

[9] https://www.youtube.com/watch?v=QbknnXlF-co

[10] W. Lewin, For the Love of Physics (Free Press, New York, 2011).

[11] https://www.ifi.unicamp.br/ lunazzi/F530_F590_F690 F809_F895/F809/F609_2014_sem1/Experimentos_para_ aula_de_teoria.htm

[12] https://youtu.be/2Yu2lyNnmkI?t=82

[13] https://www.youtube.com/watch?v=r7NEI_C9Yh0

[14] http://math.ucr.edu/home/baez/physics/General/Light Mill/light-mill.html

[15] J. Witzel, IEEE Instrumentation and Measurement 5, $60(2002)$.

[16] A. Ashkin, Physical review letters 24, 156 (1970).

[17] D. Wolfe, A. Larraza e A. Garcia, Physics of Fluids 28, 037103 (2015). 
[18] https://arxiv.org/abs/2008.04074

[19] http://www1.fisica.org.br/fne/phocadownload/Vol08Num1/v08n01a051.pdf

[20] https://www.researchgate.net/publication/51956754_R adiation_pressure_on_a_moving_body_Beyond_the_Doppl er_effect

[21] I. Silva, Rev. Bras. Ens. Fís. 37, 4 (2015).

[22] D. Halliday, R. Resnick e J. Walker, Fundamentos de Física-Óptica e Física Moderna (LTC, Rio de Janeiro, 2017), $10^{\mathrm{a}}$ ed.

[23] http://teacher.pas.rochester.edu/phy122/Lecture_Note s/Index.html

[24] A. Tufaile e A.P.B. Tufaile, Da Física do Faraó ao Fóton (Editora Livraria da Física, São Paulo, 2013).

[25] V.S. Zanuto, Pressão de Radiação: sobre os efeitos das forças de radiação em água. Tese de Doutorado, Universidade Estadual de Maringá, Maringá (2015).

[26] https://www.planetary.org/.

[27] https://www.researchgate.net/publication/337696978

[28] http://news.cornell.edu/stories/2004/06/thomas-goldcornell-astronomer-and-brilliant-scientific-gadfly-dies84, acessado em 24/01/2020.

[29] https://arxiv.org/abs/physics/0306050

[30] P.N. Lebedev, Ann. Phys. (Leipzig) 6, 433 (1901).

[31] E.F. Nichols e G.F. Hull, Phys. Rev. 13, 307 (1901).

[32] https://www.researchgate.net/publication/324536086.

[33] https://www.researchgate.net/publication/225279459_ Solar_Sails_Optical_Tweezers_and_Other_Light-Driven_ Machines

[34] http://lilith.fisica.ufmg.br/ dsoares/wst/wst.htm

[35] https://www.youtube.com/watch?v=RhkxIq7DK0Q 